\title{
Need for Formal Specialization in Pharmacy in Canada: A Survey of Hospital Pharmacists
}

\author{
Jonathan Penm, Neil J MacKinnon, Derek Jorgenson, Jun Ying, and Jennifer Smith
}

\begin{abstract}
Background: The Blueprint for Pharmacy was a collaborative initiative involving all of the major pharmacy associations in Canada. It aimed to coordinate, facilitate, and be a catalyst for changes required to align pharmacy practice with the health care needs of Canadians. In partial fulfilment of this mandate, a needs assessment for specialist certification for pharmacists was conducted.
\end{abstract}

Objective: To conduct a secondary analysis of data from the needs assessment to determine the perceptions of hospital pharmacists regarding a formal certification process for pharmacist specialties in Canada.

Methods: A survey was developed in consultation with the Blueprint for Pharmacy Specialization Project Advisory Group and other key stakeholders. It was distributed electronically, in English and French, to Canadian pharmacists identified through national and provincial pharmacy organizations (survey period January 15 to February 12, 2015). Data for hospital pharmacists were extracted for this secondary analysis. Multivariable logistic regression analyses were conducted to characterize those respondents who supported the certification process and those intending to become certified if a Canadian process were introduced.

Results: A total of 640 responses were received from hospital pharmacists. Nearly $85 \%$ of the respondents $(543 / 640$ [84.8\%]) supported a formal certification process for pharmacist specialization, and more than $70 \%$ $(249 / 349$ [71.3\%]) indicated their intention to obtain specialty certification if a Canadian process were introduced. Respondents believed that the main barriers to developing such a system were lack of reimbursement models, the time required, and lack of public awareness of pharmacist specialties. They felt that the most important factors for an optimal certification process were a consistent definition of pharmacist specialty practice and consistent recognition of pharmacist specialty practice across Canada. Multiple regression analysis showed that female respondents were more likely to support a formal certification process (odds ratio [OR] 2.6, 95\% confidence interval [CI] 1.2-5.7). Also, those who already specialized in pharmacotherapy were more likely to support mandatory certification (OR 2.6, 95\% CI 1.1-6.1).

Conclusions: Hospital pharmacists who responded to this survey overwhelmingly supported certification for pharmacist specialization in Canada. Questions remain about the feasibility of establishing a pharmacist specialization system in Canada.

Keywords: survey, hospital pharmacy, specialization, certification

\section{RÉSUMÉ}

Contexte : Le Plan directeur pour la pharmacie était un projet collaboratif auquel participaient les plus importantes associations canadiennes de pharmacie. Il cherchait à coordonner, faciliter et catalyser les changements nécessaires pour harmoniser la pratique de la profession avec les besoins en soins de santé des Canadiens. Une évaluation des besoins pour un système de certification des pharmaciens spécialistes a été menée dans le cadre de ce projet.

Objectif : Réaliser une analyse secondaire des données recueillies lors de l'évaluation des besoins afin de cerner les opinions des pharmaciens d'hôpitaux en ce qui touche au mécanisme formel de certification pour les spécialités en pharmacie au Canada.

Méthodes : Un sondage a été mis au point en consultation avec le Groupe consultatif sur le projet de spécialisation en pharmacie, sous l'égide du Plan directeur pour la pharmacie, et d'autres parties prenantes clés. Le sondage a été transmis par voie électronique, en anglais et en français, aux pharmaciens canadiens grâce aux organismes de pharmacie provinciaux et nationaux (l'enquête a eu lieu du 15 janvier au 12 février 2015). Cette analyse secondaire a porté sur le sous-ensemble des données relatives aux pharmaciens d'hôpitaux. Des analyses de régression logistique multivariable ont été réalisées afin d'offrir un portrait des répondants qui sont partisans d'un mécanisme de certification et de ceux qui ont signalé leur intention d'obtenir la certification si un processus canadien était mis en place.

Résultats : Au total, on a obtenu 640 réponses de pharmaciens d'hôpitaux. Près de $85 \%$ des répondants $(543 / 640$ [84,8 \%]) appuyaient un mécanisme formel de certification pour la spécialisation en pharmacie et plus de $70 \%$ (249/349 [71,3\%]) ont indiqué leur intention d'obtenir une certification de spécialiste si un processus canadien était mis en place. Les répondants croyaient que les principaux obstacles au développement d'un tel système étaient l'absence de modèles de remboursement, le temps nécessaire et l'ignorance du public en matière de spécialités en pharmacie. Selon eux, un processus de certification optimal reposerait principalement sur une définition uniforme de la pratique spécialisée pour les pharmaciens et une reconnaissance systématique de la pratique spécialisée pour les pharmaciens partout au Canada. Une régression multiple a montré que les répondantes étaient plus enclines à appuyer un processus formel de certification (risque relatif approché [RRA] de 2,6, intervalle de confiance [IC] à $95 \%$ de 1,2-5,7). De plus, les répondants déjà spécialisés en pharmacothérapie étaient plus susceptibles d'être partisans d'une certification obligatoire (RRA de 2,6, IC à $95 \%$ de 1,1-6,1). 


\section{Can J Hosp Pharm. 2016;69(5):356-66}

Conclusions : Les pharmaciens d'hôpitaux ayant répondu à ce sondage appuyaient presque tous un mécanisme de certification pour la spécialisation en pharmacie au Canada. Par contre, certaines questions demeurent à propos de la viabilité d'un système de spécialisation en pharmacie au Canada.

Mots clés : sondage, pharmacie hospitalière, spécialisation, certification

\section{INTRODUCTION}

$\mathrm{I}_{\mathrm{b}}^{\mathrm{n}}$ $\mathrm{n}$ most jurisdictions in Canada, hospital pharmacists have become integrated members of the health care team. The Hospital Pharmacy in Canada 2013/2014 Report highlighted that the profession has "passed the tipping point" and is now primarily focused on patient-centred care and its associated responsibilities and accountabilities. ${ }^{1}$ The same report stated that hospital pharmacists were spending more than half of their time on clinical activities and that $90 \%$ and $80 \%$ of hospitals in Canada had a pharmacist assigned to inpatient and outpatient programs, respectively. ${ }^{1}$ With hospital pharmacists in Canada becoming routinely involved with the patient care team, many of them are choosing to specialize in select areas of practice to ensure the highest standards of pharmaceutical care for their patients.

At the time of writing (late 2016), no credentialing system exists in Canada to certify and recognize pharmacists who practise as pharmacist specialists. As such, some choose to obtain certification through the US Board of Pharmacy Specialties (BPS) or the US Commission for Certification in Geriatric Pharmacy. Although such certification is voluntary in both Canada and the United States, Haines ${ }^{2}$ has argued that certification will become increasingly important as the public's and employers' demand for greater accountability and quality intensifies. Furthermore, some evidence has emerged that BPS certification has positive effects on patient outcomes. Dorsch and others $^{3}$ showed that US hospitals with BPS-certified pharmacotherapy specialists who had added qualifications in cardiology performed significantly better in terms of process-of-care metrics related to medication use than did hospitals whose pharmacists did not have such certification and qualifications. The Hospital Pharmacy in Canada 2013/2014 Report stated that it may be time for Canada to reconsider establishing its own board certification program or to find a suitable way to adapt and/or formally recognize US certification programs more consistently throughout the country. ${ }^{1}$

Canada's Blueprint for Pharmacy initiative, launched in 2008, reinvigorated the debate about pharmacist specialization and was the impetus for the current study. The Blueprint for Pharmacy was a long-term collaborative initiative designed to coordinate, facilitate, and be a catalyst for the changes required to align pharmacy practice with the health care needs of Canadians. ${ }^{4}$ Its vision for pharmacy was "Optimal drug therapy outcomes for Canadians through patient-centred care." ${ }^{4}$ The Canadian Council on Continuing Education in Pharmacy (CCCEP) took a leadership role in implementing Action 1.7 of the Blueprint's Implementation Plan, which called for "programs to upgrade knowledge, skills and values to support current practice and services, the implementation of new professional pharmacy services, specialty practices, or new practice models." 5

In 2010, the CCCEP hosted the Continuing Professional Development/Continuing Education Policy Summit: Advancing Innovation and Excellence in Pharmacy Practice. This meeting was convened "to develop the policy framework and support systems that enable continuing professional development to support practice change and continuing competence." ${ }^{5}$ To ensure that all perspectives were included in the discussion, representatives from several stakeholder groups participated in the summit, including national and provincial pharmacy associations, pharmacy technician associations, provincial regulatory authorities, faculties of pharmacy, pharmacy student associations, and continuing education program providers. ${ }^{5}$ One outcome was a recommendation for a needs assessment for specialist certification, and the Blueprint for Pharmacy commissioned such a needs assessment to be conducted. ${ }^{6}$ Because hospital pharmacists have traditionally been more likely to pursue certification and to work with patients having complex care needs, this study was undertaken to analyze hospital pharmacists' perceptions regarding the need for a formal recognition and certification process for pharmacist specialties in Canada.

\section{METHODS}

This study was a secondary analysis of a needs assessment for specialist certification for pharmacists in Canada. Questions in the survey instrument were based on current literature about pharmacist specialization and were developed in consultation with the Blueprint for Pharmacy Specialization Project Advisory Group and other key stakeholders to ensure content validity. ${ }^{6}$ The initial survey was made available in English and French and 
was pretested, in both languages, with the Blueprint for Pharmacy Specialization Project Advisory Group, the research team, and staff members of the Canadian Pharmacists Association (a mixed sample of 20 pharmacists and employers in hospital and community pharmacy). ${ }^{6}$ The results of analysis of responses from all study participants have been reported elsewhere. ${ }^{6}$

\section{Survey Questions}

The specific survey questions for each respondent depended on whether respondents classified themselves as practising pharmacists or as pharmacist employers. Those who classified themselves as both practising pharmacists and pharmacist employers were instructed to identify as an employer and to answer only the questions pertinent to employers. ${ }^{6}$

Practising pharmacists were to answer 32 questions about demographic characteristics, current specialization status, perspectives regarding future demand for practice specialization and the need for a formal Canadian certification system for specialization, and ideas regarding barriers and facilitators to implementing a specialty certification system. Respondents were also asked to rate, on a 5-point Likert scale from "strongly agree" to "strongly disagree", the barriers and important factors for an optimal certification process in Canada. Pharmacist employers were asked questions similar to those posed to the practising pharmacists, except that questions related to current specialization status and pursuit of specialization were removed. In total, pharmacist employers were asked to respond to 18 questions. The entire survey is available in Appendix C of Needs Assessment of Specialization in Pharmacy in Canada. ${ }^{6}$

In the survey, pharmacists were asked to indicate whether they identified as a specialist, according to whether they met the Blueprint for Pharmacy's definition ${ }^{6}$ (which was included in the survey):

Pharmacist specialists: maintain an active clinical practice that is limited to a particular type of patients (e.g., geriatrics, ambulatory care), part of the body (e.g., cardiology), medical condition (e.g., infectious disease, oncology), or location of practice (e.g., critical care). Specialties can be either broad (e.g., pharmacotherapy specialists, who have an advanced practice that covers complex issues arising from a broad range of medical conditions for a wide variety of patients and diseases) or focused (e.g., oncology or cardiology specialists, who have a practice that covers medically complex patients for a limited range of medical conditions in a specific patient group). Pharmacy specialization requires an advanced body of knowledge distinct of the general practitioner and a specialized or enhanced depth of competency including knowledge, skills, attitudes and accountabilities based on the physical, social, and health sciences, sufficient to manage the most complex of cases and provide clinical leadership in the field. Pharmacist specialists have completed additional clinical training in their specialty area, beyond typical entry to practice credentials, which may include the completion of formal educational programs and/or extensive clinical experience. Generally, specialty competencies attained through formal learning/ education programs and practice in the field are recognized through a certification process.

Specialization was considered to focus on medical conditions or patients with complex care needs, rather than disease state management. As such, certified diabetes or asthma educators were not considered pharmacist specialists.

\section{Survey Procedures}

Pharmacists in Canada were contacted by email, with an invitation to participate and a link to the online survey (supported by web survey software; FluidSurveys, Ottawa, Ontario). The survey was made available on January 15, 2015, and closed on February 12, 2015. Two e-mail reminders were sent, at 2-week intervals, to those who had not opened the survey link and those who had started the survey but had not completed it. To increase participation, respondents who completed the survey were entered in a draw, with a chance to win one of three $\$ 100$ gift cards. The survey took about 20-25 min to complete. Participants were unable to complete the survey more than once.

The survey invitation was distributed to pharmacists and pharmacist employers in the databases of the Canadian Pharmacists Association and the Canadian Society of Hospital Pharmacists. Survey-related communications and the link to the survey were also sent to the following associations and groups for distribution to pharmacists and pharmacist employers in their respective databases: the Canadian Association of Pharmacy in Oncology, the Association of Faculties of Pharmacy of Canada, the Association des pharmaciens des établissements de santé du Québec, the Association québécoise des pharmaciens propriétaires, the Prince Edward Island Pharmacists Association, the Ontario Pharmacists Association, the British Columbia Pharmacy Association, Costco pharmacies, Remedy's Rx pharmacies, Pharmasave pharmacies, Shoppers Drug Mart pharmacies, Brunet pharmacies, and Metro pharmacies in Ontario.

\section{Data Analysis}

Responses from pharmacists who stated that they worked in the hospital setting were extracted for the secondary analysis presented here; responses from those who stated that they were students or worked outside Canada were excluded. Although respondents were asked to indicate all of their professional credentials, the responses were recoded to reflect each person's highest professional credential, to allow more direct comparison with data in the Hospital Pharmacy in Canada 2013/2014 Report. ${ }^{7}$ Thematic analysis of open-text responses was conducted by one of the authors (J.P.) and discussed with the team until 
consensus was reached. Thematic analysis was completed using Excel software (Microsoft Corp, Redmond, Washington). The study protocol was considered exempt from ethics approval, according to the University of Cincinnati Institutional Review Board.

Descriptive statistics were used to provide an overview of respondents' demographic characteristics and their views of a formal certification process for pharmacist specialization in Canada. To ensure that enough responses were received to represent the 6500 hospital pharmacists in Canada, ${ }^{8}$ the sample size calculation proposed by Krejcie and Morgan ${ }^{9}$ was used. Using the proposed formula, a sample size of 364 was considered representative.

Univariate and multiple logistic regression analyses were conducted to assess which groups of respondents were more likely to support the creation of a formal certification process for pharmacist specialization in Canada. Additional regression analyses were conducted for respondents who considered themselves to be pharmacist specialists. These latter analyses focused on whether respondents thought the formal certification process should be mandatory for pharmacists who want to practise in a specialty area and whether they themselves would seek specialist certification in the future if a Canadian process were introduced. Analyses involving multiple comparisons were adjusted using the Bonferroni method. To create a binomial response for the logistic regression analyses, responses on the 5-point Likert scale (from "strongly agree" to "strongly disagree") were collapsed into 2 categories: "agree" and "disagree". Responses of "neither agree nor disagree" and "don't know" were removed from the regression analyses, as they were deemed to not fit into either of these categories. ${ }^{10}$ SAS software, version 9.4 (SAS Institute Inc, Cary, North Carolina), was used for all data analyses, and $p$ values less than 0.05 were considered statistically significant. When 2 or more groups were compared against the reference group for the same factor, Bonferroni-adjusted $p$ values were used in the regression analyses.

The following independent variables were considered in the logistic regression analyses: respondents' highest professional credential, age, and geographic region of practice. For the regression analyses involving respondents who considered themselves to be pharmacist specialists, the respondent's specialty area was also included as an independent variable.

The original categories for respondents' highest professional credential and age did not have sufficient sample sizes to detect statistical differences. Therefore, the data for these 2 variables were recoded to ensure that each category had at least 5 respondents either agreeing or disagreeing with the outcome variables. ${ }^{11}$ Data for highest professional credential were recoded by grouping respondents with an entry-to-practice or postbaccalaureate doctor of pharmacy degree into a single category called "doctor of pharmacy degree". Similarly, those with a master's degree in hospital or clinical pharmacy and those who had completed a hospital pharmacy residency program or board certification from the US-based Board of Pharmacy Specialties were collapsed into a single category called "residency". Age was collapsed into 2 categories: under 45 years and 45 years or older. Similarly, only the top 4 specialty areas were included in the analysis, to meet the sample-size requirement (the full list of specialty areas is presented in Table 1).

No assumptions were made for missing data; multiple regression analyses were performed on data only for participants with complete data.

\section{RESULTS}

In total, 640 responses were received: 18 from pharmacist employers and the remaining 622 from employed pharmacists working in the hospital setting. In total, $84.8 \%$ (543/640) of the respondents supported the creation of a formal certification and credentialing process for pharmacist specialization in Canada. Furthermore, of those who supported the creation of a formal certification process, 53.4\% (290/543) felt that, should formal pharmacist specialty certification become available, it should be mandatory for pharmacists who want to practise in a specialty area.

Some respondents did not complete all questions, which resulted in missing data, but among those who did respond, 66.2\% (413/624) considered themselves pharmacist specialists. Among those who considered themselves specialists and who responded to the question, $71.3 \%$ (249/349) stated that they would seek formal specialty certification in the future if a Canadian process were introduced. The primary specialty areas of practice among those who considered themselves pharmacist specialists were oncology (23.2\% [96/413]), pharmacotherapy (17.2\% [71/413]), anticoagulation (16.7\% [69/413]), and geriatrics $(16.2 \%$ [67/413]). Data for additional demographic characteristics are reported in Table 1.

\section{Factors Affecting Specialization}

Three main themes were identified among respondents' reasons for not pursuing formal certification: pharmacist specialization is not formally recognized in Canada in their respective practice areas, a certification and credentialing process is not readily available in Canada, and certification is not required to practise in their respective specialty areas (Table 2). Supplementary qualitative analysis of the open-text sections of the survey showed that effort and resources required to prepare for the examination, lack of recognition by the employer, use of US-specific information (such as guidelines) and a nonmetric system for units of measure in the examination, and lack of reimbursement programs were additional barriers to pursuing certification through the US-based BPS system. 
Table 1. Demographic Characteristics of Respondents

\begin{tabular}{|c|c|c|}
\hline \multirow{2}{*}{$\begin{array}{l}\text { Characteristic } \\
\text { Highest level of formal pharmacy education/training }(n=624)\end{array}$} & \multicolumn{2}{|c|}{ No. (\%) of Respondents } \\
\hline & & \\
\hline Bachelor of Science in Pharmacy & 220 & (35.3) \\
\hline Entry-to-practice Doctor of Pharmacy & 12 & (1.9) \\
\hline Postbaccalaureate Doctor of Pharmacy & 32 & (5.1) \\
\hline Hospital pharmacy residency program & 168 & $(26.9)$ \\
\hline Master's degree in hospital or clinical pharmacy & 159 & (25.5) \\
\hline Board certification by the US-based Board of Pharmacy Specialties & 33 & $(5.3)$ \\
\hline \multicolumn{3}{|l|}{ Currently practising as a pharmacist specialist $(n=624)$} \\
\hline Yes, formally certified & 64 & $(10.3)$ \\
\hline Yes, not formally certified & 349 & (55.9) \\
\hline No & 211 & (33.8) \\
\hline \multicolumn{3}{|l|}{$\operatorname{Sex}(n=635)$} \\
\hline Male & 162 & $(25.5)$ \\
\hline Female & 473 & $(74.5)$ \\
\hline \multicolumn{3}{|l|}{ Age (years) $(n=635)$} \\
\hline$<25$ & 19 & (3.0) \\
\hline $25-34$ & 216 & (34.0) \\
\hline $35-44$ & 182 & $(28.7)$ \\
\hline $45-54$ & 134 & $(21.1)$ \\
\hline $55-64$ & 73 & $(11.5)$ \\
\hline$\geq 65$ & 11 & $(1.7)$ \\
\hline \multicolumn{3}{|l|}{ Geographic region of practice $(n=640)$} \\
\hline British Columbia, Yukon, Nunavut, Northwest Territories & 88 & $(13.8)$ \\
\hline Alberta, Saskatchewan, and Manitoba (Prairies) & 140 & $(21.9)$ \\
\hline Ontario & 145 & $(22.7)$ \\
\hline Quebec & 225 & $(35.2)$ \\
\hline $\begin{array}{l}\text { New Brunswick, Nova Scotia, Prince Edward Island, } \\
\text { Newfoundland and Labrador (Atlantic Canada) }\end{array}$ & 42 & (6.6) \\
\hline \multicolumn{3}{|l|}{ For pharmacy specialists, certification obtained $(n=71)$} \\
\hline Board of Pharmacy Specialties & 33 & $(46.5)$ \\
\hline Commission for Certification in Geriatric Pharmacy & 10 & $(14.1)$ \\
\hline Other & 28 & $(39.4)$ \\
\hline \multicolumn{3}{|l|}{ For pharmacy specialists, area of specialty $(n=413)^{*}$} \\
\hline Oncology & 96 & $(23.2)$ \\
\hline Pharmacotherapy & 71 & $(17.2)$ \\
\hline Anticoagulation & 69 & $(16.7)$ \\
\hline Geriatrics & 67 & $(16.2)$ \\
\hline Pain and palliative care & 48 & $(11.6)$ \\
\hline Critical care & 46 & $(11.1)$ \\
\hline Cardiology & 40 & (9.7) \\
\hline Psychiatric & 35 & (8.5) \\
\hline Pediatrics & 32 & (7.7) \\
\hline Diabetes mellitus & 27 & (6.5) \\
\hline Ambulatory care & 22 & (5.3) \\
\hline Emergency medicine & 21 & (5.1) \\
\hline Primary care/family medicine & 15 & (3.6) \\
\hline Respiratory & 14 & (3.4) \\
\hline Smoking cessation & 14 & (3.4) \\
\hline Asthma & 7 & (1.7) \\
\hline Nutrition support & 7 & (1.7) \\
\hline Women's health & 7 & (1.7) \\
\hline International travel & 3 & (0.7) \\
\hline
\end{tabular}

* Respondents could choose more than one specialty area. 
This single copy is for your personal, non-commercial use only.

For permission to reprint multiple copies or to order presentation-ready copies for distribution, contact CJHP at cjhpedit@cshp.ca

Table 2. Factors That Deterred Respondents from Pursuing Formal Certification

\begin{tabular}{|c|c|c|}
\hline Factor & No. $(\%)$ & $\begin{array}{l}\text { Respondents } \\
=349)^{*}\end{array}$ \\
\hline $\begin{array}{l}\text { Pharmacist specialization is not formally recognized in } \\
\text { Canada in my practice area }\end{array}$ & 225 & (64.5) \\
\hline Pharmacist specialty certification is not readily available in Canada & 199 & $(57.0)$ \\
\hline I do not require certification to practise in my specialty area & 184 & $(52.7)$ \\
\hline $\begin{array}{l}\text { My employer does not support certification (e.g., pay for studies, } \\
\text { exam, and/or certification process) }\end{array}$ & 144 & $(41.3)$ \\
\hline $\begin{array}{l}\text { Pharmacist specialty certification is not currently available } \\
\text { in my specialty area }\end{array}$ & 134 & $(38.4)$ \\
\hline $\begin{array}{l}\text { There is limited demand for specialty certification } \\
\text { (e.g., patients don't ask to see my credentials when I provide } \\
\text { specialty care to them) }\end{array}$ & 124 & $(35.5)$ \\
\hline I do not have enough time in my schedule to become certified & 123 & $(35.2)$ \\
\hline $\begin{array}{l}\text { There is no government program available in my province that } \\
\text { would allow me to recover some of the costs of certification }\end{array}$ & 122 & $(35.0)$ \\
\hline It is too expensive to obtain formal certification & 112 & $(32.1)$ \\
\hline There is no funding formula for the delivery of specialty services & 97 & $(27.8)$ \\
\hline $\begin{array}{l}\text { Pharmacist specialty certification is not accessible for me } \\
\text { (e.g., language, travel requirements) }\end{array}$ & 73 & $(20.9)$ \\
\hline $\begin{array}{l}\text { There is a little support for pharmacist specialization from } \\
\text { other health care providers }\end{array}$ & 71 & $(20.3)$ \\
\hline $\begin{array}{l}\text { I have chosen instead to pursue additional authorization in a } \\
\text { specific practice area (or skill) such as prescribing authority } \\
\text { (Alberta) or an extended practice (Manitoba) }\end{array}$ & 33 & (9.5) \\
\hline I'm not interested in becoming certified at this time & 32 & $(9.2)$ \\
\hline
\end{tabular}

* Respondents could choose more than one factor.

Although respondents supported the creation of a formal certification and credentialing process for pharmacist specialization in Canada, they identified several barriers to developing such a system, including lack of reimbursement models for specialty clinical services in Canada, the time and cost required to become formally certified, and a lack of public awareness of the need for and role of pharmacist specialties (Figure 1). Respondents identified a consistent definition of pharmacist specialty practice and consistent recognition of pharmacist specialty practice across Canada as the most important factors for an optimal certification process (Figure 2). No differences were identified between employers and employed pharmacists working in the hospital setting in terms of barrier and facilitators.

For the logistic regression analyses, all models achieved a good fit, with $p>0.05$ for the Hosmer-Lemeshow goodness-offit statistic. Results of the univariate logistic regressions regarding respondents' support for the creation of a formal certification process for pharmacist specialization in Canada are presented in Table 3. In these analyses, female respondents (odds ratio [OR] 2.3, 95\% confidence interval [CI] 1.1-4.9) and those from Quebec (OR 3.2, 95\% CI 1.2-8.5) had significantly higher odds of supporting the creation of a formal certification process, relative to male respondents and those from outside Quebec, respectively. Respondents from Ontario (OR 0.3, 95\% CI 0.2-0.7) had significantly lower odds of supporting the creation of a formal certification process compared with those from outside Ontario. However, when multiple variables were accounted for in the logistic regression, only the result for female respondents (OR 2.6, 95\% CI 1.2-5.7) remained significant (Table 4).

Results of the univariate logistic regressions regarding pharmacy specialists' support for a mandatory certification process are presented in Table 3. In this analysis, those who specialized in pharmacotherapy had significantly higher odds of supporting mandatory certification (OR 2.6, 95\% CI 1.2-5.5). Specialization in pharmacotherapy remained the only significant variable in the multiple regression analysis (OR 2.6, 95\% CI 1.1-6.1; Table 4).

Results of the univariate logistic regressions regarding whether pharmacy specialists would pursue certification if a Canadian process were introduced are presented in Table 3. In this analysis, those under 45 years of age had significantly higher odds of pursuing certification (OR 3.6, 95\% CI 1.4-9.0). Age remained the only significant variable in the multiple regression analysis (OR 3.7, 95\% CI 1.3-9.9; Table 4). All multiple regression models had a concordance statistic of 0.7 or above, which indicated that they all achieved acceptable discrimination.

\section{DISCUSSION}

To the authors' knowledge, this study is the first to show substantial support for the creation of a formal certification and credentialing process for pharmacist specialization among Canadian hospital pharmacists. The multiple regression analyses showed that this support did not vary on the basis of age, highest 


\begin{tabular}{|l|l|l|l|l|}
\hline & Lack of reimbursement models for \\
specialty clinical services (n=611)
\end{tabular}

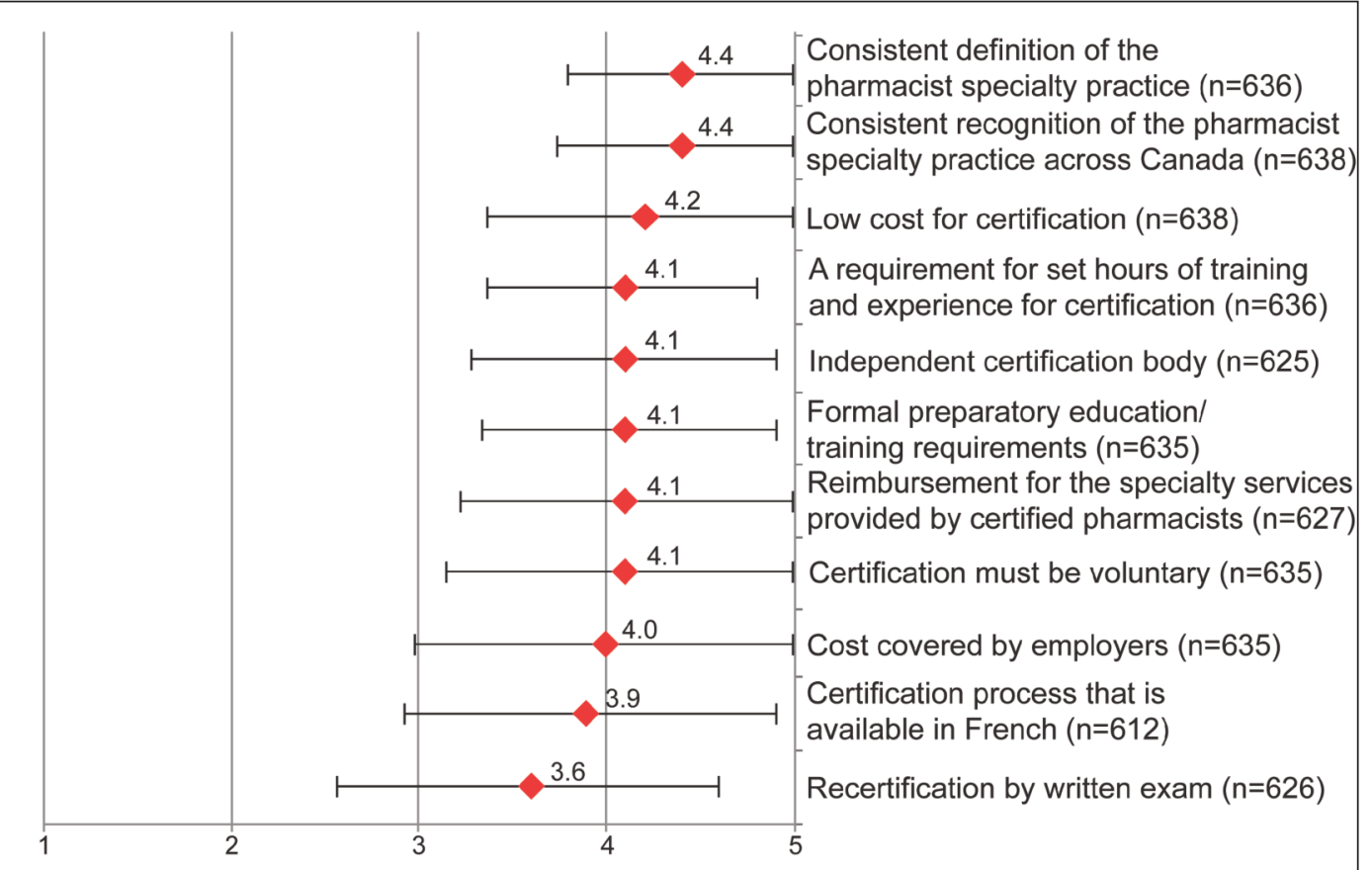

Figure 2. Important factors for an optimal pharmacist specialty certification process in Canada. Responses were recorded on a 5-point Likert scale, where $1=$ strongly disagree and $5=$ strongly agree. Responses of "don't know" were removed from the analysis. For each factor, diamond = mean, black line = standard deviation. 
This single copy is for your personal, non-commercial use only.

For permission to reprint multiple copies or to order presentation-ready copies for distribution, contact CJHP at cjhpedit@cshp.ca

Table 3. Unadjusted Odds Ratios of Perceptions Regarding a Formal Certification Process for Pharmacist Specialization in Canada

\begin{tabular}{|c|c|c|c|}
\hline \multirow[b]{2}{*}{ Characteristic } & \multicolumn{3}{|c|}{ Respondent Group; OR (95\% Cl) } \\
\hline & $\begin{array}{l}\text { Supporting Formal } \\
\text { Certification Process } \\
\qquad(n=574)\end{array}$ & $\begin{array}{l}\text { Specialists Supporting } \\
\text { Mandatory Certification } \\
\text { Process }(n=264)\end{array}$ & $\begin{array}{l}\text { Specialists Who Would } \\
\text { Pursue Certification if } \\
\text { Canadian Process Were } \\
\text { Introduced }(n=270)\end{array}$ \\
\hline \multicolumn{4}{|l|}{$\begin{array}{l}\text { Highest level of formal pharmacy } \\
\text { education/training }\end{array}$} \\
\hline Doctor of Pharmacy & $0.9(0.2-3.9)$ & $2.2(0.5-10.5)$ & $0.9(0.1-7.5)$ \\
\hline Does not have a Doctor of Pharmacy & Reference & Reference & Reference \\
\hline Residency & $1.1(0.5-2.2)$ & $1.2(0.7-2.1)$ & $1.2(0.5-3.0)$ \\
\hline Has not completed a residency & Reference & Reference & Reference \\
\hline Bachelor of Science in Pharmacy & $0.9(0.4-2.0)$ & $0.7(0.4-1.3)$ & $0.8(0.3-2.1)$ \\
\hline $\begin{array}{l}\text { Does not have a Bachelor of Science } \\
\text { in Pharmacy }\end{array}$ & Reference & Reference & Reference \\
\hline \multicolumn{4}{|l|}{ Sex } \\
\hline Women & $2.3(1.1-4.9) \neq$ & $0.8(0.4-1.5)$ & $1.4(0.5-3.6)$ \\
\hline Men & Reference & Reference & Reference \\
\hline \multicolumn{4}{|l|}{ Age (years) } \\
\hline$<45$ & $0.5(0.2-1.2)$ & $1.4(0.8-2.5)$ & $3.6(1.4-9.0) \neq$ \\
\hline$\geq 45$ & Reference & Reference & Reference \\
\hline \multicolumn{4}{|l|}{ Region } \\
\hline Prairies* & $0.9(0.4-2.1)$ & $0.8(0.4-1.5)$ & $0.7(0.2-1.8)$ \\
\hline Does not practice in Prairies & Reference & Reference & Reference \\
\hline Ontario & $0.3(0.2-0.7) \ddagger$ & $1.4(0.8-2.8)$ & $0.8(0.3-2.3)$ \\
\hline Does not practice in Ontario & Reference & Reference & Reference \\
\hline Quebec & $3.2(1.2-8.5) \neq$ & $1.0(0.6-1.7)$ & $1.7(0.6-4.5)$ \\
\hline Does not practice in Quebec & Reference & Reference & Reference \\
\hline Atlantic Canada† & $2.1(0.3-15.6)$ & $2.2(0.5-10.5)$ & $1.3(0.2-10.2)$ \\
\hline Does not practice in Atlantic Canada & Reference & Reference & Reference \\
\hline $\begin{array}{l}\text { British Columbia, Yukon, Nunavut, } \\
\text { or Northwest Territories }\end{array}$ & $1.1(0.4-3.2)$ & $0.7(0.3-1.4)$ & $0.9(0.2-3.1)$ \\
\hline $\begin{array}{l}\text { Does not practice in British Columbia, Yukon, } \\
\text { Nunavut, or Northwest Territories }\end{array}$ & Reference & Reference & Reference \\
\hline \multicolumn{4}{|l|}{ Specialty area } \\
\hline Anticoagulation & NA & $1.9(0.8-4.3)$ & $0.6(0.2-1.6)$ \\
\hline Does not specialize in anticoagulation & & Reference & Reference \\
\hline Geriatrics & NA & $1.1(0.5-2.2)$ & $0.4(0.1-1.1)$ \\
\hline Does not specialize in geriatrics & & Reference & Reference \\
\hline Oncology & NA & $1.2(0.7-2.2)$ & $2.0(0.6-7.0)$ \\
\hline Does not specialize in oncology & & Reference & Reference \\
\hline Pharmacotherapy & NA & $2.6(1.2-5.5) \neq$ & $0.7(0.2-2.3)$ \\
\hline Does not specialize in pharmacotherapy & & Reference & Reference \\
\hline
\end{tabular}

$\mathrm{Cl}=$ confidence interval, $\mathrm{NA}=$ not applicable, $\mathrm{OR}=$ odds ratio.

*Prairies = Alberta, Saskatchewan, and Manitoba

†Atlantic Canada = New Brunswick, Nova Scotia, Prince Edward Island, and Newfoundland and Labrador.

¥The OR is significant $(p<0.05)$.

professional degree obtained, or geographic region of practice across Canada. Furthermore, many of the respondents who were already practising as specialists stated that they would seek specialist certification if a Canadian process were introduced.

Despite this strong support, lack of reimbursement models for specialty clinical services in Canada was considered a major barrier to a formal certification process for pharmacist specialties. However, reimbursement models have not been a major driver for BPS certification in the United States. ${ }^{2}$ Previous research has shown that financial incentives are often not the most effective motivator in health care. ${ }^{12}$ Instead, recognition and ownership of the service have been identified as more effective motivators. ${ }^{12}$ As such, pharmacists may be less concerned with the financial incentives linked to the reimbursement models and more focused on the recognition and importance that the health system directs toward pharmacists by providing such reimbursements.

Hospital pharmacists were divided as to whether certification should be mandatory. Respondents reported that mandatory certification may be too financially stressful and time-consuming for individual pharmacists and employers for it to be viable. ${ }^{13}$ 
This single copy is for your personal, non-commercial use only.

For permission to reprint multiple copies or to order presentation-ready copies for distribution, contact CJHP at cjhpedit@cshp.ca

Table 4. Adjusted Odds Ratio of Perceptions Regarding a Formal Certification Process for Pharmacist Specialization in Canada

\begin{tabular}{|c|c|c|c|}
\hline \multirow[b]{2}{*}{ Characteristic } & \multicolumn{3}{|c|}{ Respondent Group; OR (95\% Cl) } \\
\hline & $\begin{array}{l}\text { Supporting Formal } \\
\text { Certification Process } \\
(n=574)\end{array}$ & $\begin{array}{l}\text { Specialists Supporting } \\
\text { Mandatory Certification } \\
\text { Process }(n=264)\end{array}$ & $\begin{array}{l}\text { Specialists Who Would } \\
\text { Pursue Certification if } \\
\text { Canadian Process Were } \\
\text { Introduced }(n=270)\end{array}$ \\
\hline \multicolumn{4}{|l|}{$\begin{array}{l}\text { Highest level of formal pharmacy } \\
\text { education/training* }\end{array}$} \\
\hline Doctor of Pharmacy & $0.9(0.2-4.7)$ & $3.5(0.7-18.0)$ & $1.2(0.1-12.3)$ \\
\hline Residency & $0.7(0.3-1.7)$ & $1.7(0.8-3.4)$ & $0.8(0.3-2.3)$ \\
\hline Bachelor of Science in Pharmacy & Reference & Reference & Reference \\
\hline \multicolumn{4}{|l|}{ Sex } \\
\hline Women & $2.6(1.2-5.7) \dagger$ & $0.8(0.4-1.5)$ & $1.1(0.4-3.2)$ \\
\hline Men & Reference & Reference & Reference \\
\hline \multicolumn{4}{|l|}{ Age (years) } \\
\hline$<45$ & $0.5(0.2-1.2)$ & $1.3(0.8-2.4)$ & $3.7(1.3-9.9) \dagger$ \\
\hline$\geq 45$ & Reference & Reference & Reference \\
\hline \multicolumn{4}{|l|}{ Region* } \\
\hline Prairies (Alberta, Saskatchewan, Manitoba) & $0.8(0.2-2.8)$ & $1.6(0.6-4.3)$ & $0.7(0.1-3.7)$ \\
\hline Ontario & $0.4(0.1-1.3)$ & $2.4(0.9-6.3)$ & $0.6(0.1-3.4)$ \\
\hline Quebec & $2.4(0.6-9.3)$ & $1.3(0.6-3.1)$ & $1.3(0.3-6.2)$ \\
\hline $\begin{array}{l}\text { Atlantic Canada (New Brunswick, } \\
\text { Nova Scotia,Prince Edward Island, } \\
\text { Newfoundland and Labrador) }\end{array}$ & $1.5(0.2-14.1)$ & $5.8(1.0-32.9)$ & $1.3(0.1-15.0)$ \\
\hline $\begin{array}{l}\text { British Columbia, Yukon, Nunavut } \\
\text { and Northwest Territories }\end{array}$ & Reference & Reference & Reference \\
\hline \multicolumn{4}{|l|}{ Specialty area } \\
\hline \multicolumn{4}{|l|}{ Specialization in anticoaqulation } \\
\hline Yes & NA & $1.8(0.7-4.3)$ & $0.8(0.2-2.6)$ \\
\hline No & & Reference & Reference \\
\hline \multicolumn{4}{|l|}{ Specialization in geriatrics } \\
\hline Yes & NA & $0.9(0.4-2.0)$ & $0.4(0.1-1.2)$ \\
\hline No & & Reference & Reference \\
\hline \multicolumn{4}{|l|}{ Specialization in oncology } \\
\hline Yes & NA & $1.7(0.9-3.3)$ & $1.6(0.4-5.9)$ \\
\hline No & & Reference & Reference \\
\hline \multicolumn{4}{|l|}{ Specialization in pharmacotherapy } \\
\hline Yes & NA & $2.6(1.1-6.1) \dagger$ & $0.6(0.1-2.3)$ \\
\hline No & & Reference & Reference \\
\hline
\end{tabular}

This finding is consistent with concerns that have been raised in the United States, where certification is not mandatory, even though it has been available for decades. ${ }^{2}$ The American College of Clinical Pharmacy primarily endorses BPS certification for pharmacy educators and residents who care for patients with complex pharmacotherapeutic needs. ${ }^{14}$ Further research is required to identify areas where pharmacists' specialty certification leads to higher-quality patient care and outcomes, while also being financially viable (aspects that were outside the scope of the current survey study).

The multivariable analysis also showed that those specializing in pharmacotherapy were more likely to support mandatory certification, but were no more likely to become certified if a
Canadian process were introduced, relative to other respondents. Those specializing in pharmacotherapy are unique, in that they are considered "advanced generalists", whereas other specialties focus on a single therapeutic field. ${ }^{15}$ This generalist scope places these pharmacists in a variety of settings with patients of varying complexity in terms of medical needs. As such, these pharmacists may have the most variable levels of training, with undefined prerequisites to prepare them for this role. Hence, they may support mandatory certification to standardize the care offered to their patients. However, specialization in any field, including pharmacotherapy, is generally not demanded or even recognized by employers, the public, or other health care professionals. Thus, no specialty area appeared more likely to pursue certification than any other, as it is not expected of them, nor is it formally 
recognized or reimbursed. With a lack of public awareness of pharmacist specialties being one of the highest-rated barriers in this study (Figure 1), enhanced public awareness should be a high priority for supporting the development of pharmacist specialization in Canada.

When examining the financial viability of a program for credentialing pharmacist specialists, it is important to consider the BPS certification process in the United States. The BPS system has been a leading example of pharmacist specialization around the world. Initially, the BPS was not a free-standing agency, and it could not financially support its own operations. ${ }^{16}$ Over the years, increased interest in pharmacist specialization in the United States has led increasing numbers of pharmacists to pursue BPS certification: from 3636 in 2002 to nearly 25000 in 2015 , an increase of nearly $600 \% \cdot{ }^{17}$ However, given that there are only 6500 hospital pharmacists in Canada, sustainability of a certification program would depend on a large majority pursuing certification. ${ }^{8}$ The low number of Canadian pharmacists desiring certification led many respondents in this study to raise concerns about the costs of sustaining a formal certification process. Similar concerns have been raised by pharmacy organizations in other countries with low populations, where pharmacist specialization is being explored. ${ }^{18}$

Australia, which has a similar number of pharmacists to Canada, ${ }^{19,20}$ is currently trialing an alternative system to certify advanced practice pharmacists, to reduce the financial burden associated with the US-based BPS model. In 2012, Australia developed a framework to support the recognition of advanced pharmacy practitioners in all areas of pharmacy practice. ${ }^{21} \mathrm{~A}$ pilot program to credential a small sample of advanced pharmacy practitioners was launched in 2014, with plans for full implementation in the future. ${ }^{22}$ To ensure that the process is financially sustainable, the Australian Pharmacy Council, which is responsible for credentialing advanced practice pharmacists, chose not to hold any exams or require any residency programs. ${ }^{23}$ Instead, pharmacists are credentialed on the basis of a portfolio of evidence mapped against each of the advanced practice competencies. ${ }^{23}$ Although pharmacists may use the US-based BPS exam as evidence of advanced clinical knowledge, completion of this exam is not required. The only mandatory evaluation component required for the portfolio is multisource feedback, whereby the pharmacist obtains feedback from the employer, peers, and subordinates as evidence of his or her practice standards. ${ }^{23}$ There is also an interview process for credentialing through the Australian Pharmacy Council; however, the purpose of the interview is to clarify and confirm the validity and authenticity of the evidence in the portfolio, not to assess knowledge or skills. ${ }^{23}$ Although advanced pharmacy practice and pharmacist specialization are not interchangeable, the Australian process may be viable in both circumstances and may address the financial concerns expressed by hospital pharmacists in the current survey.

\section{Limitations}

This study may have been prone to selection bias, because participants were contacted through pharmacy associations with voluntary membership. This potential bias may have resulted in only highly motivated or engaged hospital pharmacists receiving the survey, as they are more likely to be members of these associations. The fact that $27 \%$ of the respondents in this study had completed a Canadian Pharmacy Residency Boardaccredited residency program, compared with only $20 \%$ of those who responded to the 2013/2014 Hospital Pharmacy in Canada survey, supports the possibility of a small degree of selection bias in the current study. ${ }^{7}$ However, this was the only noticeable difference between the respondents in these 2 studies: respondents' province of practice, experience, and highest level of formal pharmacy education or training were comparable. ${ }^{7}$

Nonresponse bias could not be analyzed in the current study, as demographic data for nonresponders were not available to the research team and therefore could not be assessed. In addition, multiple pharmacy associations were used to contact respondents for this study. Hospital pharmacists may be members of multiple associations, so the total number of unique pharmacists who received the survey could not be determined, and thus the response rate could not be calculated. Furthermore, the regression results may not be generalizable, because missing data and neutral responses were not included in the analysis.

\section{CONCLUSION}

Canadian hospital pharmacists who responded to this survey overwhelmingly supported the creation of a formal certification and credentialing process for pharmacist specialization in Canada, with many stating that they would pursue certification if a Canadian process were introduced. Barriers to the development of such a process in Canada were identified, and questions remain about the feasibility of establishing a pharmacist specialization system in Canada.

\section{References}

1. Bussières JF, Jones R. Chapter B: Clinical pharmacy practice. In: Bonnici A, Bornstein C, Bussières JF, Doucette D, Hall K, Jones R, et al., editors. Hospital pharmacy in Canada 2013/2014 report. Eli Lilly Canada; 2015 [cited 2016 Sep 6]. pp. 3-16. Available from: www.lillyhospitalsurvey.ca/hpc2/ content/2015_report/FULL-2015.pdf

2. Haines ST. Does board certification really matter? Pharmacotherapy. 2014;34(8):799-802.

3. Dorsch MP, Lose JM, DiDomenico RJ. The effect of cardiovascular credentialed pharmacists on process measures and outcomes in myocardial infarction and heart failure. Pharmacotherapy. 2014;34(8):803-8.

4. Task Force on a Blueprint for Pharmacy. Blueprint for pharmacy: implementation plan. Ottawa (ON): Canadian Pharmacists Association; 2009.

5. Summary report: CPD/CE Policy Summit: Advancing innovation and excellence in pharmacy practice. Ottawa $(\mathrm{ON})$ : Canadian Council on Continuing Education in Pharmacy; Canadian Pharmacists Association; 2010 [cited 2016 Sep 5]. Available from: www.cccep.ca/file/Summary\%20 Report\%20CPD-CE\%20Policy\%20Summit\%20EN\%20(final).pdf

6. Intergage Consulting Group Inc. Needs assessment of specialization in pharmacy in Canada. Ottawa (ON): Canadian Pharmacists Association; 2015 [cited 2016 May 12]. Available from: www.pharmacists.ca/cpha-ca/assets/File/ 
cpha-on-the-issues/Needs\%20Assessment $\% 20$ of $\% 20$ Specialization $\% 20$ in $\%$ 20Pharmacy\%20in\%20Canada\%20-\%20Final\%20Report.pdf

7. Hall K, Bussières JF. Chapter J: Front-line pharmacists survey. In: Bonnici A, Bornstein C, Bussières JF, Doucette D, Hall K, Jones R, et al., editors. Hospital pharmacy in Canada 2013/2014 report. Eli Lilly Canada; 2015 [cited 2016 Sep 6]. pp. 120-133. Available from: www.lillyhospitalsurvey.ca/hpc2/ content/2015_report/FULL-2015.pdf

8. Pharmacists in Canada. Ottawa (ON): Canadian Pharmacists Association; [cited 2016 May 12]. Available from: www.pharmacists.ca/index.cfm/ pharmacy-in-canada/pharmacists-in-canada/

9. Krejcie RV, Morgan DW. Determining sample size for research activities. Educ Psychol Meas. 1970;30(3):607-10.

10. Garland R. The mid-point on a rating scale: Is it desirable? Market Bull. 1991;2(1):66-70.

11. Rosner B. Fundamentals of biostatistics. 7th ed. Boston (MA): Brooks/Cole; 2011.

12. Aiken C, Keller S. The irrational side of change management. McKinsey $Q$. 2009;2:100-9.

13. Brown TE. Should the provincial colleges of pharmacy create a category for "advanced practice pharmacist"? The "con" side. Can J Hosp Pharm. 2009;62(5):420-1.

14. Loewen P. Should all pharmacists responsible for pharmacotherapeutic management of patients with complex or special drug therapy needs have certification from the Board of Pharmacy Specialties? The "con" side. Can J Hosp Pharm. 2012;65(3):232-3.

15. Council on Credentialing in Pharmacy. Credentialing and privileging of pharmacists: a resource paper from the Council on Credentialing in Pharmacy. J Am Pharm Assoc. 2014;54(6):e354-64.

16. Laven DL. A review on specialization in pharmacy-Part I. J Pharm Pract. 2002;15(3):267-78

17. About BPS: History. Board of Pharmacy Specialties celebrates 40th anniversary. Washington (DC): Board of Pharmacy Specialties; [cited 2016 Sep 6]. Available from: www.bpsweb.org/about-bps/history/

18. Advanced practice and specialisation in pharmacy: global report 2015. The Hague (Netherlands): International Pharmaceutical Federation; 2015.

19. National statistics: provincial/territorial statistics - pharmacists (as of January 1, 2016). Ottawa (ON): National Association of Pharmacy Regulatory Authorities; 2016 [cited 2016 May 12]. Available from: http://napra.ca/ pages/Practice_Resources/National_Statistics.aspx?id=2103

20. Pharmacy registrant data: March 2015. Melbourne (Australia): Pharmacy Board of Australia; 2015 [cited 2016 May 12]. Available from: www. pharmacyboard.gov.au/About/Statistics.aspx. Select "Registration data table - March 2015”.
21. An advanced pharmacy practice framework for Australia. Canberra (Australia): Advanced Pharmacy Practice Framework Steering Committee; 2012.

22. Low J. Credentialing of advanced pharmacy practice. J Pharm Pract Res. 2014;44(1):11-2.

23. Matthews A. Formalising the professional development journey: credentialing of advanced practice pharmacists pilot program [slide presentation]. Canberra (Australia): Australian Pharmacy Council; 2015 [cited 2016 May 12]. Available from: https://www.pharmacycouncil.org.au/media/1093/appresentation.pdf

Jonathan Penm, BPharm(Hons), PhD, is a Postdoctoral Fellow with the James L Winkle College of Pharmacy, University of Cincinnati, Cincinnati, Ohio.

Neil J MacKinnon, BSc(Pharm), MSc(Pharm), PhD, is Professor and Dean of the James L Winkle College of Pharmacy, University of Cincinnati, Cincinnati, Ohio.

Derek Jorgenson, BSP, PharmD, is an Associate Professor of Pharmacy with the College of Pharmacy and Nutrition, University of Saskatchewan, Saskatoon, Saskatchewan.

Jun Ying, MA, MSA, PhD, is an Associate Professor of Biostatistics with the College of Medicine, University of Cincinnati, Cincinnati, Ohio.

Jennifer Smith, MA, is President of Intergage Consulting Group Inc, Ottawa, Ontario

Competing interests: None declared.

Address correspondence to:

Dr Jonathan Penm

James L Winkle College of Pharmacy

University of Cincinnati

3225 Eden Avenue

Cincinnati $\mathrm{OH} 45267$

e-mail: jonathan.penm@uc.edu

Funding: This work was funded by the Blueprint for Pharmacy Initiative. 